Session 3592

\title{
The Model Mentor: A Telephone Survey of Mentoring Experiences Among Women Engineering Faculty
}

\author{
Terri Estkowski, Liwana Bringelson, Mary Ann Bowman \\ Engineering Management Research Laboratory \\ Department of Industrial and Manufacturing Engineering, Western Michigan University
}

\section{Introduction}

In their study of mentoring from the mentor's perspective, Blackburn, Chapman and Cameron ${ }^{[1]}$ conclude that there are questions left unanswered about mentoring, such as, "What are the attributes of successful mentors" (p. 326). Hunt and Michael ${ }^{[2]}$ provide an extensive list of "Research Issues on Mentorship," including, "What characteristics must individuals have to be effective as mentors" (p. 484). Merriam ${ }^{[3]}$ writes, "As yet, studies from educational settings reveal no clear notion of how a mentor is different from an influential teacher and, if they can be differentiated, how pervasive mentoring is in this setting" (p. 169).

Based on these suggestions for future study and the Bringelson and Bowman ${ }^{[4]}$ mailed survey results, the following research questions were developed. For a woman engineering faculty member:

1. How prevalent is mentoring?

2. What are the defining characteristics of a good, effective mentor?

3. What functions does a mentor perform in a career enhancing mentoring relationship?

While it is the goal of every research endeavor to provide as complete explanations as possible of the phenomena being examined, one study cannot answer all the questions related to mentoring in higher education. Thus, there are four boundaries placed to govern the scope of this work. First, this study provides no comparison of male and female mentoring experiences. Instead, the research question is approached from the perspective of studying this population in terms of itself and the existing literature base. Second, this research does not explore the link between mentoring and the participants' feelings of success. Exploring mentoring within the context of the respondent's feelings of career success was avoided to prevent confounding of the data with respect to how the respondents defined success, if in that definition they felt successful, and what role a mentor played in that. Third, this work deliberately excludes some issues associated with hindrances to mentoring. These include men who are afraid to mentor for fear of reprisal (i.e., sexual harassment accusations and the rumor-mill) and the relatively few senior women available to mentor junior women. ${ }^{[5,6]}$ While these issues are discussed, the focus of this work is on what makes mentoring relationships that help women proteges, rather than on what hinders the initiation of the relationship. Finally, the study throughout avoids defining the term "mentoring." Jacobi ${ }^{[7]}$ cites 15 different definitions of the word "mentor" from higher education, management and organizational behavior, and psychological literature. Because of the broad range of definitions, it seemed apparent that leading the respondents to any one of them could result in confusion or misinterpretation. 


\section{Research Strategy}

An overall research strategy was adopted to facilitate an accelerated acquisition of data. Because this study began at the end of a conventional academic year (late April/early May), it was critical to begin interviews with respondents as soon as possible, before the population left their institutions for the summer. As the study was on a restricted budget, excessive phone calls, large mailings of advance letters, or additional interviewers were not considered as options to increase the study's progress. Therefore, a unique telephone interviewing strategy was developed using electronic mail and computer-generated facsimile advance letter delivery to accelerate survey administration, minimize cost, and maximize productivity.

\section{Results and Discussion}

Based on the $70 \%$ response rate, it can be conjectured that this population thought the survey was important to them. The importance is further reinforced by the fact that six potential respondents, $4.6 \%$, requested interviews after the study closed, and two of these requests came after the study had been closed for two months. Another indication of the population's response to this research is the data shown in Figure 1. This figure shows 63 respondents scheduled interviews after the first contact attempt, and 39 more were interviewed after two contact attempts. When $49.2 \%$ of the total population schedules interviews after two contact attempts, it would appear that the population identifies with the topic and wants to share their experiences.

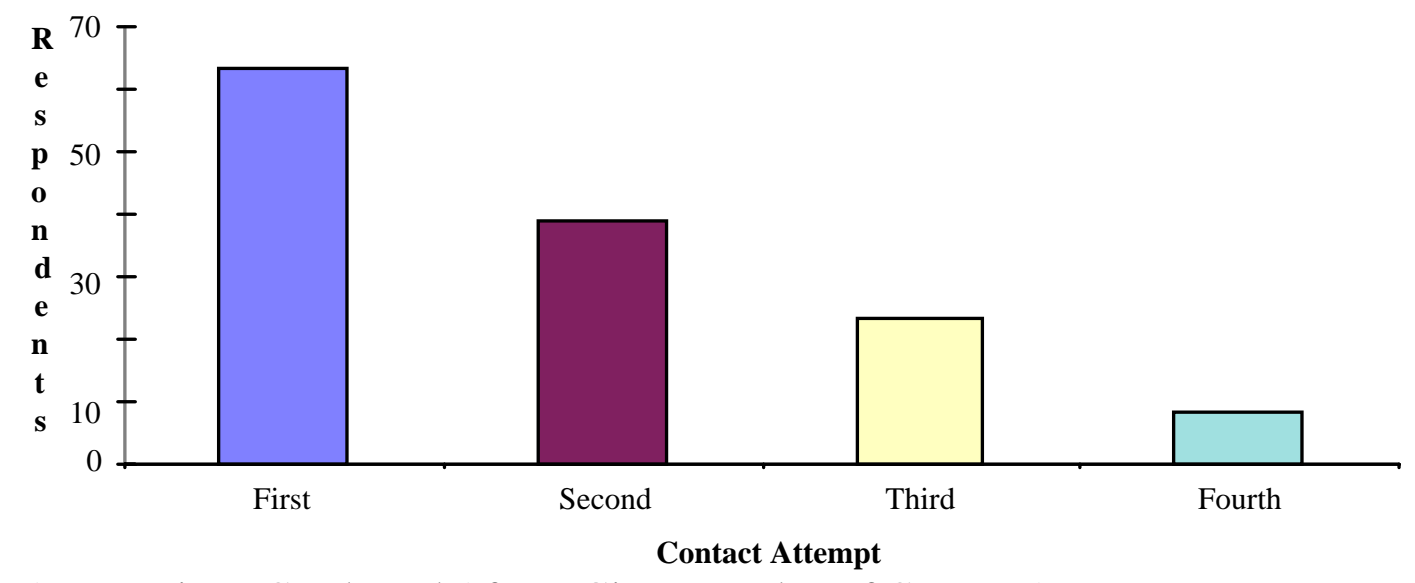

Figure 1. Interviews Conducted After a Given Number of Contact Attempts

Overall, $65.3 \%$ of the population was mentored in the first four years of their careers. However, another $31 \%$ of the population felt they had never been mentored, ever. Figure 2 data also indicate that there is a "now or never" situation. Either a mentor is found in the first year, or it is likely there will be no mentoring. With a scant $17.8 \%$ of respondents being mentored in years two to four, it appears that finding a mentor after the first year is increasingly rare. 


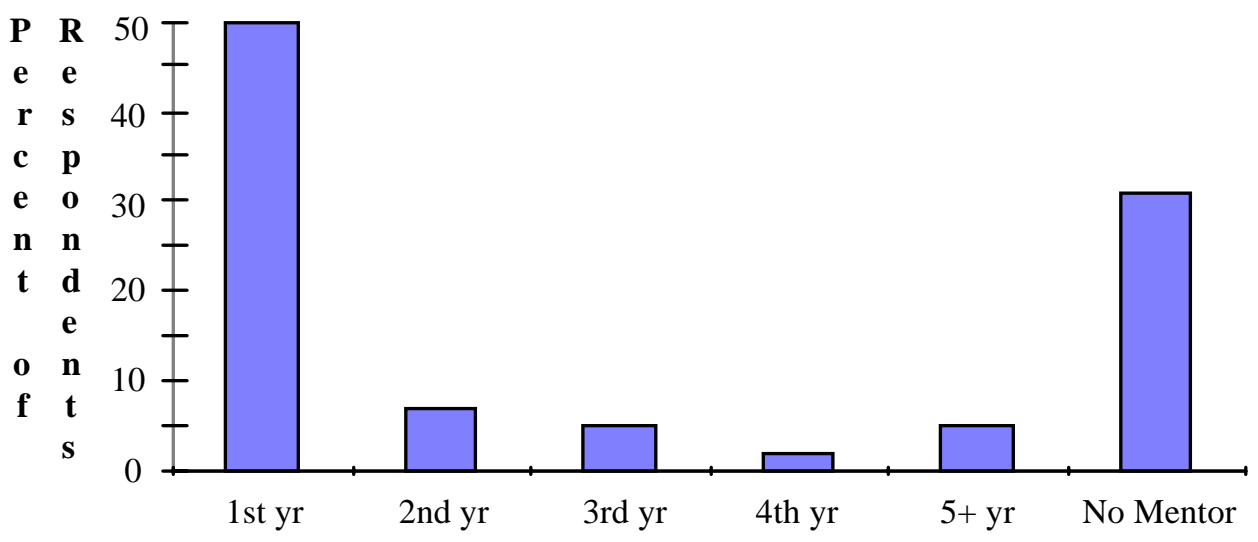

Timing in Faculty Career of First Mentoring Experience

Figure 2. Reported Timing in Faculty Career of First Mentoring Experiences

Mentoring for one year or longer was reported by $97 \%$ of those responding to the question. This is in direct agreement with mentoring definitions implying longevity in a mentoring relationship.

A group of questions asked respondents what functions a good mentor would perform. Five mentoring functions were cited by more than $23 \%$ of the population. Research and publication was noted by $48.4 \%$ of respondents; while tenure and time management $(27.7 \%)$, opportunities/networking (25.4\%), political and system advice (25.4\%), and teaching and student interaction $(23.1 \%)$ rounded out the top five. As noted throughout the literature, tenure is about teaching, research, and service, or "the big three" as one respondent stated, and teaching and research were directly noted by the participants.

Figure 3 shows how tenure's "big three" and the respondents" "top five" are related to tenure and the time management needed to achieve tenure. This figure illustrates the interrelationship of mentoring functions and a junior faculty member's tenure effort. (Though it is not in the "top five," including the service statistic highlights the population's interest in a mentor providing information on all aspects of tenure.)

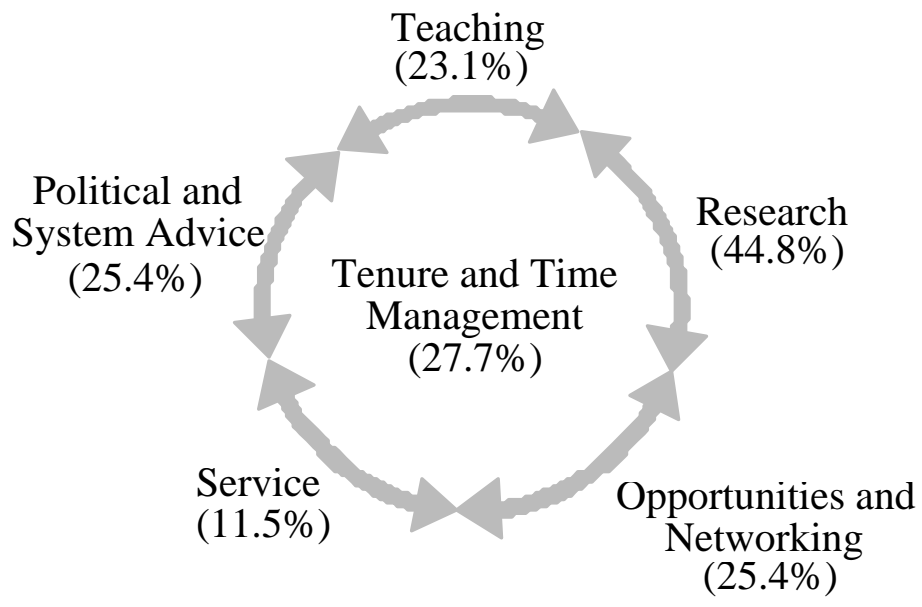

Figure 3. Interdependence of the "Big Three" Reinforced by the Respondent's Answers. 
In many ways, the "top five" and other mentoring functions paint a picture of a mentor as a tenure coach. Coaches are generally someone who has played the game, is wiser for the experience, and can direct a player from an objective position on the sidelines. Good coaches develop their team in every aspect of the game.

Another series of questions focused on the personal and professional traits a successful mentor should have. A mentor's personality (83.2\%), honesty $(82.4 \%)$, and willingness to share $(32.1 \%)$ top the list of traits respondents wanted a mentor to possess. The most important point suggested by these data is that personality matters more than performance. Conventional words describing a mentor's performance traits: knowledge/intelligence $(13.7 \%)$, politically astute and connected (8.4\%), successful (7.6\%), and experienced $(7.6 \%)$ were noted by significantly fewer respondents. Other responses reinforce the population's position on a mentor's traits.

By far, the greatest number of respondents found their mentors in their departments. While the meeting scenarios differ, the fact remains that the department mentored approximately one-third of the respondents. Nineteen of the 29 respondents citing multiple mentors had at least one mentor in their department. Combined with the 17 respondents noting an undergraduate or graduate advisor, essentially someone in their department at the time, $60.3 \%$ of respondents were mentored in either their faculty department or in another department during their post-secondary education. Grouping this with the 15 respondents noting mentors in other departments (including those with multiple mentors), $72.2 \%$ of respondents were mentored in their university.

A clear majority of respondents indicated they were involved in informal, unassigned mentoring relationships. Of the 62 respondents reporting a failed mentoring experience, 13 stated that formal, assigned mentors were the source of the failure, while 15 had negative opinions of formalized mentoring. This implies that $20.9 \%$ of failed mentoring relationships resulted from a mismatch between a mentor and protege in a formalized process, and just over $24 \%$ of respondents with a failed mentoring experience felt that formalized mentoring was not the most effective situation.

Mutual interest in a mentoring relationship seems to be the way most mentoring relationships get started $(n=50)$, with mentee-initiated mentoring being cited by 22 respondents and 21 noting mentor-initiated relationships. The responses to this question are in direct contrast to information provided in a previously mentioned study conducted by Blackburn, Chapman, and Cameron. ${ }^{[1]}$ Their study identified $43.5 \%$ of mentoring relationships as being started by mentors, with mutual initiation starting $37.1 \%$ relationships. This information is unexpected, considering the minority status of women faculty in engineering. A possible conclusion to be drawn from these data is that who initiates mentoring is not a driving force in mentoring women engineering faculty. Another conclusion might be found in statements from fourteen respondents, who felt that mentoring requires chemistry, "just happens," stems or results from collegiality or friendship, implying that mentoring success is not dependent on who started the relationship.

Two questions explored the role of time and time availability in the mentoring experiences of women engineering faculty. The first asked if respondents' time affected their ability to find a mentor, and the second addressed the effect of the potential mentor's time. For both questions, $77 \%$ of the population felt neither their time nor the mentor's time was an issue 
for them in finding a mentor. For over $10 \%$ of the respondents, mentoring was more about the right mentor than time, and just under $10 \%$ noted a focused effort to find a mentor.

A follow-up question to those on time and time availability asked about time management in an established mentoring relationship. The responses show two perspectives: efficiency and accommodation. These data support a conclusion that the concrete factors of time or who starts a mentoring relationship are not necessarily the defining points in mentoring women engineering faculty. Rather, how mentoring works to advance the protege's career defines the success of the relationship.

Sixty-two respondents reported mentoring relationships that did not end in collegiality. When explaining the problems with these relationships, 14 respondents noted lack of mentor interest on some level for a failed mentoring experience, 13 respondents $(21 \%)$ noted failed formal mentoring, and another 13 cited personality differences. These responses directly reinforce previous discussions on the importance of mentors interested in the mentee, informal mentoring, and the mentor's personality.

\section{Conclusions}

This study was conducted to develop a profile of an effective mentor for women engineering faculty based on available literature, an empirical survey, and interview data. Overall, the findings of this work increase the understanding of the preferred mentor functions and qualities. The mentor functions and qualities identified in this study indicate a career enhancing mentor

1. works in the protege's department,

2. acts as the protege's tenure coach,

3. has an agreeable personality that is compatible with the protege's,

4. interacts with the protege in an honest and respectful manner,

5. is willing to share his/her experiences, network, contacts, and time,

6. begins developing the protege early in her career, and

7. has a mentoring relationship with the protege spanning over one year.

The study also indicates that it is important that mentoring should begin as soon as possible in a faculty career. Data indicates that mentoring is unlikely to occur if it does not start in the first year. Also, with the tenure clock ticking, mentoring can not begin soon enough, considering the population's responses linking a mentor with tenure achievement.

Another finding of this study is that unmentored, tenured respondents have different needs than junior faculty members just starting the tenure process, but they could still use mentors. Tenured women need well-connected mentors who can help them continue to build their research and publication productivity and visibility.

With only $4.6 \%$ of the population noting that mentoring did not enhance their career, it is apparent that, in general, the mentoring that this population receives enhances their career. While these data can not be extended to imply that mentoring leads to success, it can be said that mentoring brings positive career results. 
Finally, unsuccessful mentoring relationships reveal a great deal about what a mentor should be. Notably, these data lead to the conclusion that formal mentoring is not the answer to providing more mentoring to women engineering faculty. Another conclusion coming from these data is that both the mentor and mentee need to be mutually interested in the relationship. Additionally, the mentor should have something to offer the mentee.

\section{Bibliography}

[1] Blackburn, R. T., Chapman, D. W., \& Cameron, S. M. (1981). "Cloning" in academe: Mentorship and academic careers. Research in higher education, 15(4), 315-27.

[2] Hunt, D. M. \& Michael, C. (1983). Mentorship: A career training and development tool. Academy of Management Review, 8(3), 475-485.

[3] Merriam, S. (1983). Mentors and proteges: A critical review of the literature. Adult Education Quarterly, 33(3), 161-173.

[4] Bringelson, L. \& Bowman, M. A. (1996). Professional experiences of women engineering faculty: A study. Unpublished. Kalamazoo, MI: WMU.

[5] Bowen, D. D. Were men meant to mentor women? Training and Development Journal 24(2): 30-34.

[6] Hall, R. M. \& Sandler, B. R. (1983). Academic mentoring for women students and faculty: A new look at an old way to get ahead. Washington, D.C.: Project on the Status and Education of Women, Association of American Colleges.

[7] Jacobi, M. (1991). Mentoring and undergraduate academic success: A literature review. Review of Educational Research, 61(4), 505-532.

\section{Biographical Information}

Terri Estkowski received her B.S in Paper Engineering from Western Michigan University in 1995. Employed by the Fort James Corporation in various manufacturing positions since that time, Terri finished her Master's degree in Engineering Management through the department of Industrial and Manufacturing Engineering at Western Michigan University. She works actively to enhance the visibility of women in science and engineering though work with gender equity groups and making presentations to grade school girls to promote science education.

Dr. Liwana Bringelson is an Associate Professor and co-founder of the Engineering Management Research Laboratory in the Industrial and Manufacturing Engineering Department at Western Michigan University. She earned her M.S. and Ph.D. in Human Factors from the School of Industrial Engineering at Purdue University. She has been actively involved in professional organizations including serving as a Director of the Women in Engineering Division of the American Society of Engineering Education since 1993.

Mary Ann Bowman is a consultant who leads diversity and communication workshops. Her years of experience as a faculty member in several U.S. universities include recent work as the Director of the Office of Faculty Development at Western Michigan University. The author of several books, Dr. Bowman conducts research and publishes articles on issues related to university teaching, with a special interest in gender equity. 